\title{
Analysis of middle- and long-term efficacy of thoracoscope-assisted segmental resection of the lung on non-small cell lung cancer in the early stage
}

\author{
NING DING, NING ZHOU, QINGLIN LI, GUANGMING REN and MIN ZHOU \\ Department of Respiratory Medicine, The Affiliated Xuzhou City Hospital of \\ Xuzhou Medical University, Xuzhou, Jiangsu 221002, P.R. China
}

Received June 20, 2017; Accepted October 10, 2017

DOI: $10.3892 / \mathrm{ol} .2018 .7789$

\begin{abstract}
We investigated the short- and long-term efficacy of thoracoscope-assisted segmental resection of lung of non-small cell lung cancer (NSCLC). We selected a total of 94 patients with lung cancer in the early stage who were admitted to The First People's Hospital of Xuzhou for treatment between March 2011 and February 2012. Patients were divided randomly into either the control group $(n=47)$ or the observation group $(n=47)$. In the observation group, patients received thoracoscope-assisted segmental resection of lung, while in the control group, the conventional thoracic surgery was performed for treatment. After surgeries, we observed the incidence rate of complications among the two groups, and enzyme-linked immunosorbent assay (ELISA) was adopted to detect levels of inflammatory factors. We also compared the cardiac and pulmonary functions, the levels of immunoglobulins and subgroups of $\mathrm{T}$ lymphocytes in the peripheral blood of the patients. In addition, all patients attended a 5-year follow-up to determine the recurrence and survival rate. Compared to the control group, patients in the observation group had significantly less intra-operative bleeding volume, a shorter duration of surgery, and suffered slighter pain after surgery $(\mathrm{P}<0.05)$. After surgery, the incidence rate of complications in the observation group was significantly lower than that in the control group $(\mathrm{P}<0.05)$. After surgeries, patients in both groups experienced a remarkable improvement in cardiac and pulmonary functions, and the improvement in the observation group was superior to that of the control group $(\mathrm{P}<0.05)$. During the 5-year follow-up, the survival rate of the observation group is significantly higher than that in thecon-
\end{abstract}

Correspondence to: Dr Min Zhou, Department of Respiratory Medicine, The Affiliated Xuzhou City Hospital of Xuzhou Medical University, 19 Zhongshan North Road, Xuzhou, Jiangsu 221002, P.R. China

E-mail: zhoumin6180@163.com

Key words: thoracoscope-assisted segmental resection of lung, non-small cell lung cancer, inflammatory factors, immune functions trol group, and patients in the observation group experienced a lower recurrence rate than those in the control group $(\mathrm{P}<0.05)$. Thus, thoracoscope-assisted segmental resection of lung is of great significance in clinical practice.

\section{Introduction}

Lung cancer is one of the most malignant tumors that are frequently seen in clinical practice. It is associated with an extremely high morbidity rate and mortality rate. Lung cancer ranks first among general malignant tumors, which can severely threaten the physical health of human beings (1). Lung cancer can be categorized into small cell lung cancer (SCLC) and non-small cell lung cancer (NSCLC). NSCLC composes almost $80 \%$ of the lung cancer cases (2). Various treatment methods have been developed for NSCLC, including surgeries, chemotherapy and radiotherapy, in which surgeries have been considered as the preferred choice for treatment of NSCLC in the early stage. After surgeries, 50-80\% patients experience a 5-year survival period $(3,4)$. With an advancement of medical techniques and instruments, thoracoscope-assisted segmental resection of lungs have become the major method in the surgical treatment of lung cancer, and shows excellent efficacy, particularly for the elderly patients or patients with poor cardiac or pulmonary functions (5). In this study, we performed thoracoscope-assisted segmental resection of lung for patients with NSCLC at the early stage, and observed the short- and long-term efficacy to provide a reference for the surgical treatment of NSCLC at the early stage.

\section{Materials and methods}

Sample selection. We selected a total of 86 patients with NSCLC that were admitted to The First People's Hospital of Xuzhou for treatment between December 2010 and December 2011. Using a random number table, we divided them in to the control group $(n=43)$ and the observation group $(n=43)$. The inclusion criteria included: a) Patients that were diagnosed with NSCLC at the early stage according to results of computed tomography (CT) and pathological examinations, b) patients with the peripheral nodule diameters $\leq 2 \mathrm{~cm}, \mathrm{c}$ ) patients without any history of surgery, chemotherapy or radiotherapy, and d) patients who 
signed the informed consent form. Exclusion criteria included, a) patients with abnormal coagulation function, b) patients with NSCLC above stage III A, c) patients with a history of thoracic surgeries, or with lymph node metastasis in hilum of lung and mediastinum or distant metastasis. Comparison of the baseline characteristics of patients between the two groups showed no statistically significant differences $(\mathrm{P}>0.05$; Table I). The study was approved by the Ethics Committee of The First People's Hospital of Xuzhou.

Pre-surgery preparation. Routine examinations were carried out before surgery for patients to exclude surgical contradiction and ascertain the optimal surgical time. At 2 weeks before surgery, patients were required to quit smoking. Food and water was withdrawn at $8 \mathrm{~h}$ before surgery.

Treatment. All patients received general intravenous anesthesia with trachea cannula in the lateral position. During surgery, the arterial blood gases, arterial blood pressure, pulse and electrocardiography were monitored. Patients in the control group received conventional thoracic surgery in following procedures. After the sterile drape was covered on the surgical site, the lateral approach was prepared for opening the chest layer by layer. The mediastinal lymph nodes were resected followed by a routine resection of lobes of the lung. Warm saline was used to rinse the thoracic cavity after the surgery, and the air leakage was examined in the lung. The residual bronchial ends with the drainage tube being detained into the chest. The incision was closed through suturing.

In the observation group, patients received the thoracoscope-assisted segmental resection of lung through 3 ports: The observation port was prepared in the 7 th and 8 th intercostal space along the midline of the lateral axillary, which is approximately $1 \mathrm{~cm}$. The main operation port was located in the intercostal space between the 4th and 5th rib along the anterior axillary line, which is approximately $3 \mathrm{~cm}$. The auxiliary operation port in the 8th intercostal space along the infrascapular line, which is approximately $1 \mathrm{~cm}$. Under the view of video, the resection of different pulmonary segments was performed with the lymph nodes being resected. After surgery, surgeons examined the dilation of residual lung, air leakage in lung or the residual bronchial end. The drainage tube was inserted into the thoracic cavity followed by suture of incision.

Indicators of detection. Before surgery and at 1 week after surgery, we collected $5 \mathrm{ml}$ of fasting peripheral venous blood from the patients in both groups, and the samples were used for enzyme-linked immunosorbent assay ELISA to determine levels of interleukin 6 (IL-6), interleukin 8 (IL-8) and tumor necrosis factor- $\alpha$ (TNF- $\alpha)$. The appropriate kits were purchased from Beijing Biolab Science and Technology Co. Ltd. (Beijing, China) and the procedures were conducted in strict accordance with the manufacturer's instructions. The levels of IL-6, IL-8 and TNF- $\alpha$ were calculated using optical density (OD) values at a wavelength of $450 \mathrm{~nm}$, detected by a microplate reader (Jiangsu Potebio Biotechnology Co., Ltd., Jiangsu, China). With kits purchased from Zhejiang Ikon Biotechnology Co., Ltd. (Zhejiang, China), immunoturbidimetry was conducted to detect levels of $\operatorname{IgG}, \operatorname{Ig} A$ and $\operatorname{IgM}$ in serum of patients in strict accordance with the instructions of the kit. The turbidity of the reaction solution was used to detect the content of $\mathrm{IgG}$, IgA and IgM in samples with the standard substance as a reference. In the samples, $\mathrm{CD}^{+}, \mathrm{CD}^{+}$and $\mathrm{CD} 8^{+}$antibodies were added, respectively, and then incubated for $30 \mathrm{~min}$ in the dark at $4^{\circ} \mathrm{C}$. Flow cytometer (BD, USA) was used to detect levels of T lymphocyte subgroups $\left(\mathrm{CD}^{+}, \mathrm{CD}^{+}\right.$and $\left.\mathrm{CD} 8^{+}\right)$.

Evaluation indicators. We compared the surgical efficacy of patients between the groups, including the intraoperative bleeding volume and the number of resected lymph nodes. After surgery, pain was evaluated using a visual analogue scale (VAS) within the range of scores between 0 and 10 points ( 0 point for no pain, and 10 points for intolerable acute pain). The comparison of postoperative complications was also conducted through recording the incidence rates of hyperthermia, persistent air leakage, cardiac arrhythmia, and pulmonary atelectasis.

Before surgery and at 1 week after surgery, $5 \mathrm{ml}$ of fasting venous blood was drawn from patients in the morning who had been fasting for $8 \mathrm{~h}$. The samples were used for detecting the levels of IL-6, IL- 8 and TNF- $\alpha$ in serum of patients through ELISA. Immunoturbidimetry was conducted to measure the levels of $\operatorname{IgG}, \operatorname{IgA}$ and $\operatorname{IgM}$, and the levels of T lymphocyte subgroups $\left(\mathrm{CD}^{+}, \mathrm{CD}^{+}, \mathrm{CD}^{+}\right.$and $\left.\mathrm{CD} 4^{+} / \mathrm{CD}^{+}\right)$were detected using flow cytometry. Before surgery and at 3 months postsurgery, we examined the cardiac and pulmonary functions of patients, including the following indicators: heart rate (HR), forced expiratory volume in one second (FEV1), maximal voluntary ventilation (MVV) and carbon monoxide-diffusing capacity (DLCO).

During the 5-year follow-up, we collected statistics of recurrence rate, disease-free survival (DFS) and 5-year survival rate, in which the DFS was defined from the 1st day after surgery to the day of first onset of recurrence or metastasis, and 5-year survival was defined as the patients had no recurrence or metastasis within the 5-year follow-up.

Statistical analysis. SPSS 19.0 (SPSS Inc., Chicago, IL, USA) was used to perform data processing. Measurement data are presented as mean \pm standard deviation, and t-test was performed for intergroup comparison. The count data were presented as a rate, and a Chi-square test was performed for comparison of countable data. The Kaplan-Meier curve was applied in the survival analysis. $\mathrm{P}<0.05$ was considered to indicate a statistically significant difference.

\section{Results}

Comparison of surgical efficacy of patients between the groups. In the observation group, the intraoperative bleeding volume of patients was significantly less than that in the control group. In addition, the surgical duration was respectively short and the postoperative pain was alleviated compared to the control group $(\mathrm{P}<0.05)$. There were no statistically significant differences in comparison of the number of resected lymph nodes of patients between the groups ( $\mathrm{P}>0.05$; Table II).

Comparison of incidence rates of postoperative complications of patients between the two groups. In the observation group, the rate of complications, including hyperthermia, persistent 
Table I. Comparison of general materials of patients between the two groups.

\begin{tabular}{lcccr}
\hline Characteristics & Control group $(\mathrm{n}=47)$ & Observation group $(\mathrm{n}=47)$ & $\mathrm{t}$-value/ $\chi^{2}$ & P-value \\
\hline Sex (male/female) & $29 / 18$ & $27 / 20$ & 0.044 & 0.836 \\
Age (years) & $40-75$ & $40-78$ & & \\
Average age (years) & $57.69 \pm 7.69$ & $58.24 \pm 7.53$ & 0.350 & 0.727 \\
Smoking (n, \%) & & & & 0.325 \\
Cigarette amount $\geq 5$ & $19(40.43)$ & $16(34.04)$ & & 0.850 \\
Cigarette amount $<5$ & $9(19.15)$ & $10(21.28)$ & & \\
No smoking & $19(40.43)$ & $21(44.68)$ & & \\
\hline
\end{tabular}

Table II. Comparison of surgical condition of patients between the two groups.

\begin{tabular}{lccccc}
\hline Group & Case & $\begin{array}{c}\text { Surgical duration } \\
(\mathrm{min})\end{array}$ & $\begin{array}{c}\text { Intraoperative bleeding } \\
\text { amount }(\mathrm{ml})\end{array}$ & $\begin{array}{c}\text { Number of resected } \\
\text { lymph nodes }(\mathrm{n})\end{array}$ & $\begin{array}{c}\text { Score of postoperative } \\
\text { pain (point) }\end{array}$ \\
\hline Observation group & 47 & $124.73 \pm 8.05$ & $216.43 \pm 11.63$ & $7.23 \pm 1.56$ & $2.58 \pm 1.57$ \\
Control group & 47 & $165.24 \pm 8.37$ & $325.86 \pm 18.78$ & $7.56 \pm 2.47$ & $5.56 \pm 1.48$ \\
t-value & & 23.951 & 33.936 & 0.774 & 9.469 \\
P-value & $<0.001$ & $<0.001$ & 0.441 & $<0.001$ \\
\hline
\end{tabular}

Table III. Comparison of the incidence rate of postoperative complications of patients between the two groups (n, \%).

\begin{tabular}{|c|c|c|c|c|c|}
\hline Group & Case & Hyperthermia & Persistent air leakage & Cardiac arrhythmia & Pulmonary atelectasis \\
\hline Observation group & 47 & $0(0.00)$ & $0(0.00)$ & $1(2.13)$ & $1(2.13)$ \\
\hline Control group & 47 & $4(8.51)$ & $3(6.38)$ & $2(4.26)$ & $4(8.51)$ \\
\hline$\chi^{2}$ & \multicolumn{5}{|c|}{7.932} \\
\hline P-value & \multicolumn{5}{|c|}{0.005} \\
\hline
\end{tabular}

air leakage ( $>1$ week), cardiac arrhythmia and pulmonary atelectasis, was $6.98 \%$, while the rate of complications in the control group was $30.23 \%$, suggesting that the rate in the observation group was significantly lower than that in the control group $(\mathrm{P}<0.05$; Table III).

Comparison of the levels of inflammatory cytokines of patients between the groups. At 1 week after surgery, the levels of TNF- $\alpha$, IL- 6 and IL- 8 of patients in both groups were remarkably elevated, and the elevation in the control group was more significant than that in the observation group $(\mathrm{P}<0.05$; Table IV).

Comparison of the cardiac and pulmonary functions of patients at 3 months after surgery between the two groups. There was significant improvement seen in the cardiac and pulmonary function of these two groups, and the improvement in the observation group was superior to that of the control group $(\mathrm{P}<0.05$; Table $\mathrm{V})$.

Comparison of immunoglobulin levels of patients between the groups. At 1 week after surgery, the levels of $\mathrm{IgG}, \mathrm{IgA}$ and $\operatorname{IgM}$ of patients of both groups were decreased, and the decrease in the control group was more significant than that in the observation group $(\mathrm{P}<0.05$; Table VI).

Comparison of levels of T lymphocyte subgroups in serum of patients between the two groups. In these two groups, the levels of $\mathrm{CD}^{+}, \mathrm{CD}^{+}, \mathrm{CD}^{+}$and $\mathrm{CD} 4^{+} / \mathrm{CD}^{+}$were decreased, and the decrease in the control group was more significant than that in the observation group $(\mathrm{P}<0.05$; Table VII $)$.

Comparison of the recurrence rate and survival of patients between the groups. In the observation group, the average survival duration of patients was significantly longer than that in the control group, the recurrence rate was significantly lower than that in the control group, and the 5-year survival rate after surgery was significantly higher than that in the control group $(\mathrm{P}<0.05$; Table VIII and Fig. 1).

\section{Discussion}

Lung cancer is the most clinically common primary malignant tumor of the lung; it is also known as bronchial lung cancer 
Table IV. Comparison of the levels of inflammatory cytokines of patients between the two groups (ng/l).

\begin{tabular}{llcccc}
\hline Group & Time & Case & TNF- $\alpha$ & IL-6 & IL-8 \\
\hline Observation group & Before surgery & 47 & $62.64 \pm 6.28$ & $56.36 \pm 4.27$ & $73.52 \pm 3.16$ \\
& After surgery & 47 & $106.56 \pm 6.63^{\mathrm{a}, \mathrm{b}}$ & $95.47 \pm 6.36^{\mathrm{a}, \mathrm{b}}$ & $117.56 \pm 8.74^{\mathrm{a}, \mathrm{b}}$ \\
Control group & Before surgery & 47 & $62.83 \pm 3.57$ & $56.74 \pm 4.52$ & $73.85 \pm 3.47$ \\
& After surgery & 47 & $123.39 \pm 8.24^{\mathrm{a}}$ & $116.56 \pm 9.53^{\mathrm{a}}$ & $135.62 \pm 9.83^{\mathrm{a}}$ \\
\hline
\end{tabular}

${ }^{\text {ap }}<0.05$ compared with the levels before surgery; ${ }^{\text {}} \mathrm{P}<0.05$ compared with the levels in the control group.

Table V. Comparison of the cardiac and pulmonary functions of patients between the two groups.

\begin{tabular}{llcllll}
\hline Group & \multicolumn{1}{c}{ Time } & Case & HR $(\mathrm{bpm})$ & FEV1 $(\%)$ & MVV $(\%)$ & DLCO (\%) \\
\hline Observation group & Before surgery & 47 & $69.87 \pm 6.54$ & $1.96 \pm 0.36$ & $68.63 \pm 3.73$ & $77.57 \pm 3.26$ \\
& After surgery & 47 & $82.76 \pm 6.75^{\mathrm{a}, \mathrm{b}}$ & $1.67 \pm 0.32^{\mathrm{a}, \mathrm{b}}$ & $74.59 \pm 3.84^{\mathrm{a}, \mathrm{b}}$ & $67.74 \pm 3.04^{\mathrm{a}, \mathrm{b}}$ \\
Control group & Before surgery & 47 & $70.32 \pm 6.18$ & $1.93 \pm 0.27$ & $69.54 \pm 3.56$ & $78.13 \pm 3.47$ \\
& After surgery & 47 & $96.53 \pm 7.43^{\mathrm{a}}$ & $1.44 \pm 0.25^{\mathrm{a}}$ & $61.57 \pm 3.14^{\mathrm{a}}$ & $71.25 \pm 3.16^{\mathrm{a}}$ \\
\hline
\end{tabular}

${ }^{a} \mathrm{P}<0.05$ compared with the levels before surgery; ${ }^{\mathrm{P}}<0.05$ compared with the levels in the control group.

Table VI. Comparison of immunoglobulin levels of patients between the two groups.

\begin{tabular}{llcccc}
\hline Group & \multicolumn{1}{c}{ Time } & Case & $\operatorname{IgG}$ & $\operatorname{IgA}$ & $\operatorname{IgM}$ \\
\hline Observation group & Before surgery & 47 & $14.64 \pm 3.28$ & $2.16 \pm 0.27$ & $1.27 \pm 0.16$ \\
& After surgery & 47 & $12.58 \pm 2.73^{\mathrm{a}, \mathrm{b}}$ & $1.87 \pm 0.18^{\mathrm{a}, \mathrm{b}}$ & $1.06 \pm 0.12^{\mathrm{a}, \mathrm{b}}$ \\
\multirow{2}{*}{ Control group } & Before surgery & 47 & $14.58 \pm 3.14$ & $2.13 \pm 0.23$ & $1.25 \pm 0.14$ \\
& After surgery & 47 & $9.57 \pm 2.15^{\mathrm{a}}$ & $1.46 \pm 0.15^{\mathrm{a}}$ & $0.97 \pm 0.08^{\mathrm{a}}$ \\
\hline
\end{tabular}

${ }^{\text {aP }}<0.05$ compared with the levels before surgery; ${ }^{\text {}} \mathrm{P}<0.05$ compared with the levels in the control group.

for its origins in the bronchial epithelium (6). Various factors can contribute to the onset of NSCLC, including smoking, occupational carcinogens, air pollution, ionized radiation, diet, nutrition and variations in genes and heritability (7). Currently, the pathogenesis of NSCLC remains unclear yet, it is believed to be caused by the malignant proliferation of mutated cells due to an adverse microenvironment in local parts (8). Affected by various factors and the invasion of exogenous carcinogens into the lung, the body initiates a routine immune mechanism to minimize damage to the pulmonary tissues and functions by limitation, neutralization, elimination and eradication. Simultaneously, seal-repair is also conducted in pulmonary tissues and functions. Once the factors that contribute to the damage cannot be eradicated thoroughly in the body, a small number of factors will be stagnated in local parts of the lung. Although this may not cause acute stress response and extensive damage to the lung, it can result in persistent inflammation of local parts, which, together with the continuous repair of the micro-damage through the repair mechanism, can lead to significant difference between affected regions and the surrounding tissues in normal metabolism. With extension of time, these parts will evolve into adverse microenvironment in the local parts, whereas cells in normal pulmonary tissues would not be able to adapt to the adverse environment, and go into a differentiation phase, which can weaken the repair capability, and facilitate loss of control, thereby forming malignant proliferation and generation of NSCLC tumors $(9,10)$.

With a continuous increase in the healthcare awareness of people and the development of modern medical imaging techniques, NSCLC is apt to be discovered at an early stage, which has brought opportunities for patients to receive the early-stage treatment, and made surgical treatment into a preferred treatment method (11). Segmental bronchi, together with a bronchial tree and surrounding pulmonary tissues, constitutes the bronchopulmonary segments, also known as pulmonary segments. There are 8 segments in the left lung, and ten in right lung with the tip in the radix pulmonis and the root on the surface of lung (12). The independent artery, 
Table VII. Comparison of levels of T lymphocyte subgroups in serum of patients between the two groups.

\begin{tabular}{llcclll}
\hline Group & \multicolumn{1}{c}{ Time } & Case & \multicolumn{1}{c}{$\mathrm{CD}^{+}$} & \multicolumn{1}{c}{$\mathrm{CD} 4^{+}$} & \multicolumn{1}{c}{$\mathrm{CD}^{+}$} & $\mathrm{CD}^{+} / \mathrm{CD} 8^{+}$ \\
\hline Observation group & Before surgery & 47 & $62.25 \pm 3.78$ & $36.85 \pm 2.27$ & $28.53 \pm 2.16$ & $1.82 \pm 0.26$ \\
& After surgery & 47 & $53.56 \pm 3.13^{\mathrm{a}, \mathrm{b}}$ & $31.43 \pm 2.16^{\mathrm{a}, \mathrm{b}}$ & $23.16 \pm 2.04^{\mathrm{a}, \mathrm{b}}$ & $1.52 \pm 0.14^{\mathrm{a}, \mathrm{b}}$ \\
Control group & Before surgery & 47 & $63.84 \pm 3.46$ & $37.13 \pm 2.24$ & $28.67 \pm 2.16$ & $1.85 \pm 0.27$ \\
& After surgery & 47 & $46.23 \pm 3.16^{\mathrm{a}}$ & $25.38 \pm 2.06^{\mathrm{a}}$ & $19.54 \pm 1.89^{\mathrm{a}}$ & $1.37 \pm 0.13^{\mathrm{a}}$ \\
\hline
\end{tabular}

${ }^{a} \mathrm{P}<0.05$ compared with the levels before surgery; ${ }^{\mathrm{P}}<0.05$ compared with the levels in the control group.

Table VIII. Comparison of the condition of patients in a five-year follow-up between the two groups.

\begin{tabular}{lcccc}
\hline Group & Case & Five-year survival (n, \%) & Recurrence rate (n, \%) & Average survival duration (month) \\
\hline Observation group & 47 & $33(70.21)$ & $2(4.26)$ & $49.76 \pm 7.75$ \\
Control group & 47 & $22(46.81)$ & $13(27.65)$ & $40.83 \pm 7.68$ \\
$\chi^{2} / \mathrm{t}-\mathrm{value}$ & & 4.382 & 7.932 & 5.611 \\
P-value & 0.036 & 0.005 & $<0.001$ \\
\hline
\end{tabular}

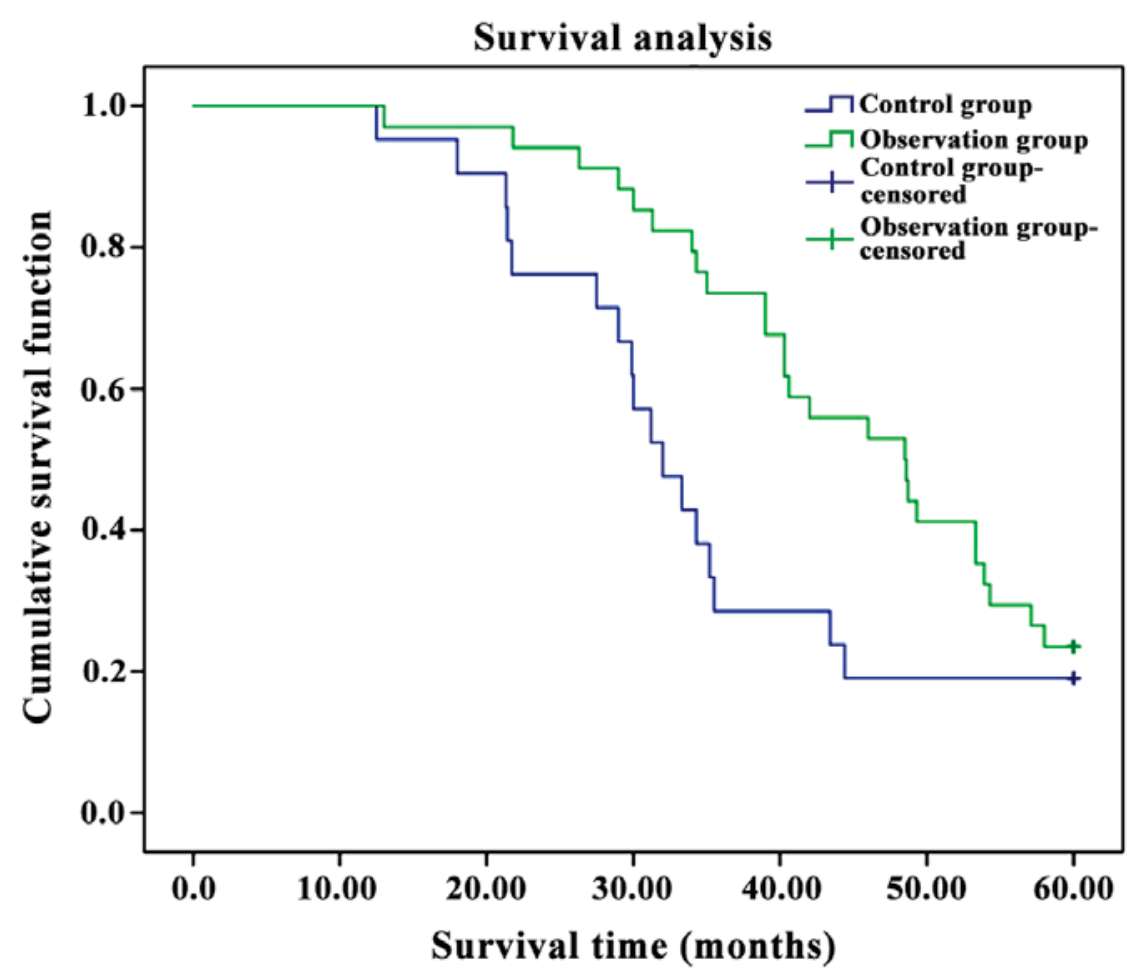

Figure 1. Survival curve of patients; the survival analysis of Kaplan-Meier at $\mathrm{P}<0.05$.

bronchi and the vein share with adjacent pulmonary segment, which consists of the independent bronchial tree and the relatively independent blood-supply circulation system into each pulmonary segment, which endows segmental resection with clinical availability (13). With a continuous development in the micro-invasive technique, thoracoscope-assisted segmental resection has become increasingly popular among elderly patients that are more susceptible to various diseases and have difficulties in conventional thoracic surgeries (14). In this study, results show that in comparison of surgical efficacy between the two groups, the intraoperative bleeding amount, surgical duration and the postoperative pain in the observation group is significantly reduced, shortened and alleviated, respectively, and the incidence rate of postoperative complications in the observation group is significantly lower than that in the control group $(\mathrm{P}<0.05)$. In addition, there was no significant difference in the comparison of the number of resected lymph nodes between the groups $(\mathrm{P}>0.05)$. The results suggest 
that thoracoscope-assisted surgery can maximally shorten the surgical duration, reduce intraoperative bleeding amount for its small surgical incision and alleviate postoperative pain. Particularly for elderly patients, this surgical method results in fewer injuries and a lower incidence rate of postoperative complications.

The results of this study show that at 1 month post-surgery, the cardiac and pulmonary function in both groups were significantly improved, and the improvement in the observation group was more significant than in the control group $(\mathrm{P}<0.05)$. This may be due to thoracoscope-assisted segmental resection, which on the premise of guaranteeing the surgical efficacy, maximally retains the function of residual lung of patients, and is superior to conventional thoracic surgery in terms of FEV1. Moreover, small surgical parts can be magnified on the video screen, alleviate the damage to the lung and effectively protect the pulmonary function of patients, which is more conducive to the postoperative recovery of patients (15).

Most NSCLC patients suffer from poor cellular immune function, and, moreover, the stress responses caused by anesthesia and surgeries will further inhibit immune functions, resulting in disorders of immune function with inflammatory reactions, and postoperative infection of patients (16). The results of this study reveal that the levels of TNF- $\alpha$, IL- 6 and IL- 8 at 1 week post-surgery in both groups were significantly increased, and the increase in the control group was more significant than those in the observation group. At 1 week postsurgery, the levels of $\operatorname{IgG}, \operatorname{IgA}$ and $\operatorname{IgM}$ of the patients in two groups were reduced, and the decreases in the control group was more significant than those in the observation group. In addition, the levels of $\mathrm{CD}^{+}, \mathrm{CD}^{+}, \mathrm{CD}^{+}$and $\mathrm{CD} 4^{+} / \mathrm{CD}^{+}$were reduced in the two groups, and the reductions in the control group were more significant than those in the observation group $(\mathrm{P}<0.05)$. This is due to the fact that thoracoscope-assisted segmental resection results in fewer traumas, slighter stress responses and less activation to the reactions in the immune system. Consequently, the secretion of inflammatory factors, including TNF- $\alpha$, IL- 6 and IL-8, is reduced. In addition, with features such as precision and micro-invasion, thoracoscope-assisted segmental resection brings less injury to normal immune functions, and scarcely affects normal postoperative levels of IgG, IgA and IgM of patients (17). In the body, $\mathrm{CD}^{+}$assists to identify the receptor of antibodies in T cells (18), CD4 ${ }^{+} \mathrm{T}$ cells, with the regulatory function in the immune system, participates in the activation of $\mathrm{CD}^{+} \mathrm{T}$ cells as an assistant role (19), and the activated $\mathrm{CD}^{+} \mathrm{T}$ cells eliminates cells infected by virus and tumor cells (20). Thoracoscope-assisted segmental resection poses lower injury on the immune functions of patients, thereby resulting in a less significant decrease in the capability of an immune response to tumors.

The results of this study show that when comparing the recurrence rate and survival of patients between the groups, the average survival duration of patients in the observation group was significantly longer than that in the control group, and the recurrence rate was significantly lower than that in the control group. The 5-year survival rate after surgery was higher than that in the control group $(\mathrm{P}<0.05)$. This is due to the slight trauma caused by thoracoscope-assisted segmental resection, which causes relatively mild inflammatory responses, little influence on immune functions, and significant short- and long-term efficacy, which remarkably augments the postoperative survival rate and prolongs survival duration of patients. In addition, the long-term efficacy of thoracoscope-assisted segmental resection is more evident than that of conventional thoracic surgery.

In conclusion, for the treatment of NSCLC, thoracoscopeassisted segmental resection has a more evident short- and long term efficacy and higher security. Thus, it is worthy of being promoted in clinical practice.

\section{References}

1. Borghaei H, Paz-Ares L, Horn L, Spigel DR, Steins M, Ready NE, Chow LQ, Vokes EE, Felip E, Holgado E, et al: Nivolumab versus docetaxel in advanced nonsquamous non-small-cell lung cancer. N Engl J Med 373: 1627-1639, 2015.

2. D'Addario G, Früh M, Reck M, Baumann P, Klepetko W and Felip E; ESMO Guidelines Working Group: Metastatic nonsmall-cell lung cancer: ESMO Clinical Practice Guidelines for diagnosis, treatment and follow-up. Ann Oncol 21 (Suppl 5): v116-v119, 2010.

3. Garon EB, Rizvi NA, Hui R, Leighl N, Balmanoukian AS, Eder JP, Patnaik A, Aggarwal C, Gubens M, Horn L, et al; KEYNOTE-001 Investigators: Pembrolizumab for the treatment of non-small-cell lung cancer. N Engl J Med 372: 2018-2028, 2015.

4. Sprung J, Scavonetto F, Yeoh TY, Kramer JM, Karnes RJ, Eisenach JH, Schroeder DR and Weingarten TN: Outcomes after radical prostatectomy for cancer: a comparison between general anesthesia and epidural anesthesia with fentanyl analgesia: a matched cohort study. Anesth Analg 119: 859-866, 2014.

5. Klapper J and D'Amico TA: VATS versus open surgery for lung cancer resection: Moving toward a minimally invasive approach. J Natl Compr Canc Netw 13: 162-164, 2015.

6. Masters GA, Temin S, Azzoli CG, Giaccone G, Baker S Jr, Brahmer JR, Ellis PM, Gajra A, Rackear N, Schiller JH, et al; American Society of Clinical Oncology Clinical Practice: Systemic Therapy for Stage IV Non-Small-Cell Lung Cancer: American Society of Clinical Oncology Clinical Practice Guideline Update. J Clin Oncol 33: 3488-3515, 2015.

7. Travis WD, Travis LB and Devesa SS: Lung cancer. Cancer 75 (Suppl): 191-202, 1995.

8. Thomas A, Liu SV, Subramaniam DS and Giaccone G: Refining the treatment of NSCLC according to histological and molecular subtypes. Nat Rev Clin Oncol 12: 511-526, 2015.

9. Grimminger PP, Maus MK, Schneider PM, Metzger R, Hölscher AH, Sugita H, Danenberg PV, Alakus H and Brabender J: Glutathione S-transferase PI (GST-PI) mRNA expression and DNA methylation is involved in the pathogenesis and prognosis of NSCLC. Lung Cancer 78: 87-91, 2012.

10. Black RC and Khurshid H: NSCLC: An update of driver mutations, their role in pathogenesis and clinical significance. R I Med J (2013) 98: 25-28, 2015.

11. Van Der Steen N, Rolfo C, Giovannetti E, Reclusa P, Peters GJ and Pauwels P: P2.09: cMET in NSCLC: Expression, amplification and mutations: track: biology and pathogenesis. J Thorac Oncol 11: S221-S222, 2016.

12. Seok Y, Cho S, Lee JY, Yang HC, Kim K and Jheon S: The effect of postoperative change in bronchial angle on postoperative pulmonary function after upper lobectomy in lung cancer patients. Interact Cardiovasc Thorac Surg 18: 183-188, 2014.

13. Cheng YD, Duan CJ, Dong S, Zhang H, Zhang SK, Wang SQ and Zhang CF: Clinical controlled comparison between lobectomy and segmental resection for patients over 70 years of age with clinical stage I non-small cell lung cancer. Eur J Surg Oncol 38: 1149-1155, 2012.

14. Laursen LØ, Petersen RH, Hansen HJ, Jensen TK, Ravn J and Konge L: Video-assisted thoracoscopic surgery lobectomy for lung cancer is associated with a lower 30-day morbidity compared with lobectomy by thoracotomy. Eur J Cardiothorac Surg 49: 870-875, 2016.

15. Goto T, Kadota Y, Mori T, Yamashita S, Horio H, Nagayasu T and Iwasaki A: Video-assisted thoracic surgery for pneumothorax: Republication of a systematic review and a proposal by the guideline committee of the Japanese association for chest surgery 2014. Gen Thorac Cardiovasc Surg 63: 8-13, 2015. 
16. Hong Y and Rurong W: Systemic and alveolar inflammatory response in the dependent and nondependent lung in patients undergoing lung resection surgery. Eur J Anaesthesiol 33: 63-64, 2016.

17. Zhang J, Wang X, Zhang Y, Wu J and Zhou N: Leucine-rich repeats and immunoglobulin-like domains protein 1 and fascin actin-bundling protein 1 expression in nonsmall cell lung cancer. J Cancer Res Ther 12 (Suppl): C248-C251, 2016.

18. Feng Q, Wei H, Morihara J, Stern J, Yu M, Kiviat N, Hellstrom I and Hellstrom KE: Th2 type inflammation promotes the gradual progression of HPV-infected cervical cells to cervical carcinoma. Gynecol Oncol 127: 412-419, 2012.

19. Erdogan Kayhan G, Gul M, Kayhan B, Gedik E, Ozgul U, Kurtoglu EL, Durmus M and Ersoy MÖ: Dexmedetomidine ameliorates TNBS-induced colitis by inducing immunomodulator effect. J Surg Res 183: 733-741, 2013.
20. Jackute J, Zemaitis M, Pranys D, Sitkauskiene B, Miliauskas S, Bajoriunas V, Lavinskiene S and Sakalauskas R: The prognostic influence of tumor infiltrating Foxp3(+)CD4(+), CD4(+) and CD8(+) T cells in resected non-small cell lung cancer. J Inflamm (Lond) 12: 63, 2015.

(i) (8) This work is licensed under a Creative Commons Attribution-NonCommercial-NoDerivatives 4.0 International (CC BY-NC-ND 4.0) License. 